\title{
Bim Expression Indicates the Pathway to Retinal Cell Death in Development and Degeneration
}

\author{
Francesca Doonan, ${ }^{1 \star}$ Maryanne Donovan, ${ }^{1 *}$ Violeta Gomez-Vicente, ${ }^{1}$ Philippe Bouillet, ${ }^{2}$ and Thomas G. Cotter ${ }^{1}$ \\ ${ }^{1}$ Tumour Biology Laboratory, Biochemistry Department, Bioscience Research Institute, University College Cork, Cork, Republic of Ireland, and ${ }^{2}$ The Walter \\ and Eliza Hall Institute of Medical Research, Melbourne, Victoria 3050, Australia
}

\begin{abstract}
Programmed cell death (PCD) during development of the mouse retina involves activation of the mitochondrial pathway. Previous work has shown that the multidomain Bcl-2 family proteins Bax and Bak are fundamentally involved in this process. To induce mitochondrial membrane permeabilization, Bax and Bak require that prosurvival members of the family be inactivated by binding of "BH3-only" members. We showed previously that the BH3-only protein BimEL is highly expressed during postnatal retinal development but decreases dramatically thereafter. The purpose of this study was to investigate a possible role for Bim, in retinal development and degeneration, upstream of Bax and Bak. Bim ${ }^{-1-}$ mice analyzed for defective retinal development exhibit an increase in retinal thickness and a delay in PCD, thereby confirming a role for Bim. We also demonstrate that in response to certain death stimuli, $\mathrm{bim}^{+/+}$retinal explants upregulate BimEL leading to caspase activation and cell death, whereas $\mathrm{bim}^{-/-}$explants are resistant to apoptosis. Finally, we analyzed Bim expression in the retinal degeneration (rd) mouse, an in vivo model of retinal degeneration. Bim isoforms, which decrease during development, are not reexpressed during retinal degeneration and ultimately photoreceptor cells die by a caspase-independent mechanism. Thus, we conclude that in cases in which BimEL is reexpressed during pathological cell death, developmental cell death pathways are reactivated. However, the absence of BimEL expression correlates with caspase-independent death in the rd model.
\end{abstract}

Key words: Bim; retina; development; apoptosis; caspase; rd

\section{Introduction}

The study of programmed neuronal cell death is an area of considerable interest given that it is implicated in both development and degeneration of the mammalian nervous system, and cells unable to make functional connections are efficiently removed by apoptosis. In addition, apoptosis is responsible for the removal of damaged cells in degenerative conditions of the retina such as retinitis pigmentosa (Li and Milam, 1995), glaucoma (Quigley et al., 1995), and agerelated macular degeneration (Dunaief et al., 2002). It has been suggested that the molecular mechanisms of apoptosis may be different under circumstances of development and degeneration, but the identity of the key regulators remains unknown (Hsu et al., 2004; Bahi et al., 2006; Donovan et al., 2006).

The intrinsic or mitochondrial pathway is a pathway widely used by cells undergoing apoptosis in response to toxic stimuli. However, previous work has shown that this pathway is not activated in a number of animal models of retinal degeneration and consequently caspases are not involved (Donovan et al., 2001; Doonan et al., 2003; Chahory et al., 2004). Because Bcl-2 family proteins control mitochondrial integrity, it is possible that they play a key role in the decision between caspase-dependent and

\footnotetext{
Received Feb. 28, 2007; revised July 26, 2007; accepted July 26, 2007.

This work was supported by the Higher Education Authority, Scientific Foundation Ireland, Health Research Board, and Fighting Blindness Ireland.

*F.D. and M.D. contributed equally to this work.

Correspondence should be addressed to Thomas G. Cotter at the above address. E-mail: t.cotter@ucc.ie.

D0I:10.1523/JNEUROSC1.0903-07.2007

Copyright $\odot 2007$ Society for Neuroscience $\quad$ 0270-6474/07/2710887-08\$15.00/0
}

-independent death (Danial and Korsmeyer, 2004). Members of this family fall into two broad categories, proapoptotic and antiapoptotic, based on their ability to elicit opposing effects at the level of the mitochondria. Those proteins with proapoptotic functions are classified further into multidomain such as Bax and Bak (containing three $\mathrm{BH}$ domains) or "BH3-only" (possessing only the BH3 domain) such as Bim, Bid, Bad, Puma, Bik, and Noxa. The proapoptotic function of $\mathrm{BH} 3$-only proteins requires Bax or Bak (Cheng et al., 2001; Wei et al., 2001; Zong et al., 2001) and an intact BH3 domain (Wang et al., 1996; Zha et al., 1997).

Bcl-2-interacting mediator of cell death (Bim), of which there are at least three isoforms BimEL, BimL, and BimS, has become firmly established as a critical mediator of neuronal apoptosis through studies of Bim overexpression or inactivation (O'Connor et al., 1998; Putcha et al., 2001; Whitfield et al., 2001). The regulation of Bim activity is complex, involving both transcriptional and posttranslational mechanisms. Both JNK (c-Jun $\mathrm{N}$-terminal kinase)/c-Jun and forkhead transcription factors contribute to transcription of Bim (Harris and Johnson, 2001; Dijkers et al., 2002; Gilley et al., 2003; Obexer et al., 2007), whereas posttranslational regulation involves rapid phosphorylation by Erk1/2 (extracellular signal-regulated kinase 1/2) resulting in its ubiquitylation, proteasomal targeting, and degradation (Biswas and Greene, 2002; Ley et al., 2003; Luciano et al., 2003).

The purpose of this study was to examine the role of the $\mathrm{BH} 3$ only protein Bim in development and degeneration of the early postnatal retina. Our findings indicate that Bim is a key regulator of apoptosis during development, with cell death delayed signif- 
icantly in its absence. We also demonstrate that retinal explant cultures exposed to calcium stress, hydrogen peroxide, or staurosporine (STS), in which BimEL is expressed at very low levels, upregulate this proapoptotic protein before caspase activation and cell death. Furthermore, $\mathrm{bim}^{-1-}$ retinas are highly resistant to each of these apoptotic stimuli. Finally, we examine the expression pattern of BimEL in the retinal degeneration (rd) model during development and degeneration to try to gain an insight into the death mechanisms involved in vivo.

\section{Materials and Methods}

Animals. C57BL/6 (wt) and C3H/HEN (rd) animals were obtained from Harlan (Bicester, UK). Generation of Bim-deficient mice (266Del strain; C57BL/6 background) has been described previously (Bouillet et al., 1999). Animals were maintained in $12 \mathrm{~h}$ light/dark cycles and killed by cervical dislocation.

Terminal deoxynucleotidyl transferase-mediated biotinylated UTP nick end labeling. Enucleated eyes were fixed in $10 \%$ neutral buffered formalin overnight at $4^{\circ} \mathrm{C}$, followed by cryoprotection in $25 \%$ sucrose overnight at $4^{\circ} \mathrm{C}$. Retinal explants were treated in the same manner. Frozen sections $(7$ $\mu \mathrm{m}$ ) were incubated with terminal deoxynucleotidyl transferase (MSC, Dublin, Republic of Ireland) and fluorescein-12-dUTP (Roche, Lewes, UK) according to manufacturers' instructions at $37^{\circ} \mathrm{C}$ for $1 \mathrm{~h}$. Sections were mounted and viewed under a fluorescence microscope (Leica DM LB2; Leica, Nussloch, Germany) using an FITC filter.

Immunohistochemistry. Whole eyes or retinal explants were fixed as described above. After antigen retrieval in $10 \mathrm{~mm}$ citrate buffer, $\mathrm{pH} 6.0$ (microwave at $650 \mathrm{~W}$ for $15 \mathrm{~min}$ ), and quenching of endogenous peroxidase activity, frozen sections $(7 \mu \mathrm{m})$ were incubated with anti-active caspase-3 (1:50) or anti-active caspase-9 (1:100) (Cell Signaling, Beverly, MA) overnight at $4^{\circ} \mathrm{C}$. Washes in PBS with $0.01 \%$ Tween 20 were followed by incubation with secondary antibody for $1 \mathrm{~h}$ at room temperature. Antibody detection was achieved with VectorStain Elite ABC kit and $\mathrm{DAB}$ reagent (Vector Laboratories, Peterborough, UK). Sections were counterstained with hematoxylin to facilitate tissue orientation and mounted in DepeX.

Retinal explants. Eyes from C57BL/6 and C57BL/6 $\mathrm{bim}^{-1-}$ mice were removed and cleaned with $70 \%$ ethanol. The anterior segment, vitreous body, and sclera were removed and the retina mounted on Millicell nitrocellulose inserts (Millipore, Billerica, MA) photoreceptor-side down. Explants were cultured without retinal pigment epithelium (RPE) in $1.2 \mathrm{ml}$ of R16 media (from Dr. P. A. Ekstrom, Wallenberg Retina Centre, Lund University, Lund, Sweden) without additional serum. Treated explants were cultured in medium containing $5 \mu \mathrm{M}$ 5-methylamino-2-(2S,3R,5R,8S,9S)-3,5,9-trimethyl2-(1-oxo-1-(1 H-pyrrol-2-yl)propan-2-yl)-1,7-dioxaspiro(5.5)undecan-8-yl) methyl)benzooxazole-4-carboxylic acid (A23187), $1 \mu \mathrm{M} \mathrm{STS}$, or $600 \mu \mathrm{M} \mathrm{H}_{2} \mathrm{O}_{2}$ (Sigma, Dublin, Republic of Ireland), respectively, for $24 \mathrm{~h}$.

Western blot analysis. After treatment, cells were scraped, washed once in PBS, and resuspended in radioimmunoprecipitation assay (RIPA) buffer. Alternatively, retinas were dissected in PBS and dissociated in RIPA buffer (Doonan et al., 2003). Equivalent amounts of protein were resolved using SDS-PAGE followed by transfer to nitrocellulose membrane (Schleicher and Scheull, Dassel, Germany). Antibodies reactive to Bim (Sigma) and GAPDH (Insight Biotechnology, Middlesex, UK) were used in this study. Membrane development was achieved using enhanced chemiluminescence (Amersham Biosciences, Buckinghamshire, UK).

$R T-P C R$. Total RNA was isolated using Trizol reagent (Bio-Sciences, Dun Laoghaire, Republic of Ireland). cDNA was synthesized from RNA samples using Moloney murine leukemia virus reverse transcriptase and oligo-dT (MSC) according to manufacturers' instructions. The primers used were as follows: bimEL, forward, 5'-GACAGAACCGCAAGGTAATCCCGACG-3', and reverse, 5'-TAGGATCCCCTCAATGCCTTCTCCATACCAG-3'; gapdh, forward, 5'-ACCACAGTCCATGCCATCAC-3', and reverse, 5' -TCCACCACCCTGTTGCTGTA-3' (MWG, Milton Keynes, UK). PCR products were separated on an agarose gel, stained with ethidium bromide, and visualized under UV light.

Data analysis. After terminal deoxynucleotidyl transferase-mediated biotinylated UTP nick end labeling (TUNEL) staining, slides were coded and analyzed by an independent observer. For each developmental stage, at least three animals were used and three fields ( $40 \times$ magnification) per section of at least three different sections were evaluated. Images of the retinal sections were obtained using a Leica fluorescence microscope. In Figure 1, the number of TUNEL-positive cells in each field was counted and calculated as a percentage over the total number of cells in the same field. To determine the total number of cells in each layer, a gridline was established. Twenty percent of the squares in each retinal layer were selected at random, and the cells in each grid were counted. This value was extrapolated to the number of squares covering each layer in the entire field. In Figure 1, we have expressed the results as relative values, because cell numbers in each retinal layer are constantly changing as a result of neuronal pruning. In Figure 4, in which only one retinal age was examined, the total cell numbers in the outer nuclear layer (ONL) would be approximately the same, and thus relative and absolute values would be the same. Therefore, the results presented in Figure 4 are presented as absolute values.

Retinal thickness was assessed at each developmental stage in at least three animals comparing three fields ( $40 \times$ magnification) per section of at least three different sections. Thickness of the ONL, inner nuclear layer (INL), and ganglion cell layer (GCL) was measured with a calibrated scale of the objective of the light microscope. Comparisons between $\mathrm{bim}^{-1-}$ and wt were performed using unpaired, two-tailed $t$ test analysis.

\section{Results}

\section{Developmental programmed cell death is delayed in retinas of bim $^{-1-}$ mice}

We have previously shown that BimEL is highly expressed at the peak of developmental programmed cell death (PCD) and is rapidly downregulated thereafter (Donovan et al., 2006). This suggests a requirement for Bim during postnatal retinal development when cells are primed to die. We assessed the potential involvement of this protein in apoptosis in the developing mouse retina in vivo using bim $^{-1-}$ mice. TUNEL staining of retinal sections from $\mathrm{bim}^{-1-}$ mice shows that the peak of death is delayed considerably in each layer (Fig. $1 A$ ). The first wave of retinal PCD, occurring normally at postnatal day 2 (P2) (Pequignot et al., 2003) in the GCL of wt retinas is delayed by $5 \mathrm{~d}$, occurring in $\mathrm{bim}^{-1-}$ retinas at P7. A second peak of GCL death occurring at P8 is also delayed, which may explain why a number of TUNELpositive cells are detected in the adult $\mathrm{bim}^{-1-}$ GCL (Fig. $1 \mathrm{~B}$ ). The waves of postnatal cell death that eliminate certain cell types from the INL were also significantly delayed. Apoptosis in this layer peaks at approximately P7/P8 in the wt compared with two separate peaks at $\mathrm{P} 11$ and $\mathrm{P} 15$ in the $\mathrm{bim}^{-/-}$retina. Although the individual cell types undergoing apoptosis were not identified in this study, excess amacrine cells (P3-P5), bipolar cells (P8-P11), and Müller glia (P8-P11) are eliminated during normal retinal development (Young, 1984). Furthermore, INL rods that fail to migrate successfully into the ONL remain temporarily in the INL where they undergo apoptosis (Young, 1984; Hahn et al., 2003). Finally, we show that the percentage of TUNEL-positive cells peaks in the wt ONL at P15 corresponding with a previous report (Pequignot et al., 2003). The percentage of TUNEL-positive cells in the ONL of P15 $\mathrm{bim}^{-/-}$retinas is much less than in wt, and significantly more dying cells were counted in the ONL of adult $\mathrm{bim}^{-/-}$retinas compared with wt, suggesting that the wave of death is also delayed.

In addition, the thickness of each of the nuclear layers was measured (Fig. 2A). Our results show that the $\mathrm{bim}^{-1-}$ ONL is significantly thicker from P7 through P15 and into adulthood. In the INL, the largest differences were detected from P5 to P8, whereas the most significant difference in the GCL is present at P0 (Fig. $2 \mathrm{~B}$ ). Furthermore, $\mathrm{bim}^{-/-}$retinas are already thicker than their wt counterparts at $\mathrm{P} 0$, implying a role for Bim in cell 


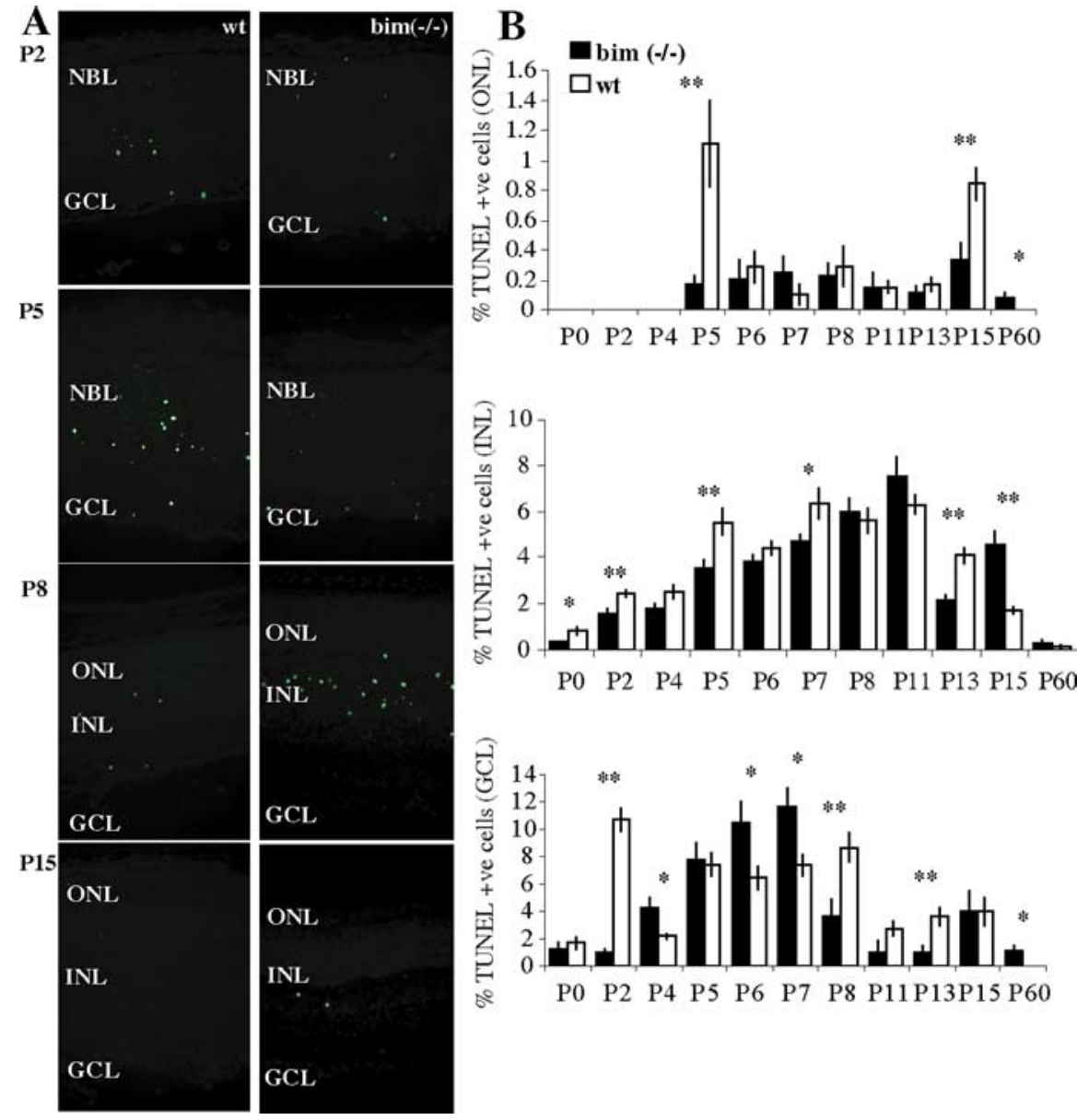

Figure 1. Developmental apoptosis in the retina is delayed in $\mathrm{bim}^{-/-}$mice. $\boldsymbol{A}$, TUNEL staining in retinal sections from $\mathrm{P} 2, \mathrm{P5}$, $\mathrm{P} 8$, and P15 mice demonstrates the pattern of cell death in wt versus bim ${ }^{-/-}$mice. NBL, Neuroblastic layer. $\boldsymbol{B}$, The number of TUNEL-positive cells in each field was counted and calculated as a percentage over the total number of cells in the same field. To determine the total number of cells, a gridline was established. Twenty percent of the squares in each retinal layer were selected at random, and the cells in each grid were counted. This value was extrapolated to the number of squares covering each layer in the entire field. Error bars represent $\pm S D\left({ }^{*} p<0.05 ;{ }^{* *} p<0.01\right)$. The ONL is not represented until P5 when the NBL separates, yielding the ONL and INL.

death during embryonic development of the mouse retina, which peaks at embryonic day 10.5 (Pequignot et al., 2003). Finally, we analyzed $\mathrm{bim}^{-1-}$ and wt retinas for caspase-9 activation to determine whether or not dying cells still activate the mitochondrial pathway in the absence of Bim, given that cell death in the absence of caspase activation has been readily detected in dying retinal cells (Donovan et al., 2001; Doonan et al., 2003; Lohr et al., 2006). We found that caspase- 9 cleavage [and caspase- 3 cleavage (data not shown)] was evident both in wt and $\mathrm{bim}^{-/-}$retinas (Fig. 2A) and that the peak of caspase activation was also delayed (data not shown). This is consistent with activation of the mitochondrial pathway, implying redundancy within the BH3-only family.

\section{Bim-deficient retinal explants are resistant to calcium overload}

Having identified an important role for Bim in developmental apoptosis, we extended our study to include models of degeneration. Retinal explants from $\mathrm{P} 10$ and $\mathrm{P} 15$ mice were used, because our previous data showed a rapid decrease in BimEL expression between these ages (Donovan et al., 2006). Treatment with $5 \mu \mathrm{M}$ calcium ionophore (A23187), which is relevant to models of retinal disease (Bouillet et al., 1999; Donovan et al., 2001; Read et al., 2002; Doonan et al., 2003; Fox et al., 2003; Takano et al., 2004), for $24 \mathrm{~h}$ induced cell death in both $\mathrm{P} 10$ and P15 explants, mostly in the ONL containing the photoreceptor cells. Cells of the INL and GCL were also affected but to a lesser degree. Our results show that P15 retinal explants are consistently more resistant than P10 retinal explants to cell death and caspase-9 processing (Fig. $3 A$ ). Protein expression of BimEL increased in response to ionophore at both $\mathrm{P} 10$ and $\mathrm{P} 15$, indicating that Bim is an important sensor of calcium stress in retinal explants (Fig. 3B). To confirm that BimEL expression is required for ionophore-induced cell death, retinal explants from $\mathrm{bim}^{-1-}$ mice were used. The amount of cell death in each panel $24 \mathrm{~h}$ after calcium treatment mirrors exactly the level of BimEL (Fig. $3 C$ ). Western blot data show induction of Bim expression in $+/+$ (wt) P15 retinal explants in response to calcium stress as described above, whereas the level of BimEL is greatly reduced in $+/-$ explants and undetectable in $-/-$ explants (Fig. $3 D$ ). Caspase- 9 processing is detected in the $-/-$ panel suggesting that the remaining TUNEL-positive cells die in a caspasedependent manner (Fig. 3E).

\section{Bim-deficient retinal explants are also resistant to oxidative stress and STS}

We showed that induction of Bim expression in response to calcium overload plays an important role in activation of the mitochondrial pathway and cell death. Given that distinct BH3-only proteins seem to induce apoptosis in response to specific death stimuli, we wanted to determine whether or not Bim is a sensor for death in response to other stimuli. Hence we exposed retinal explants from $\mathrm{bim}^{-/-}$mice to oxidative stress (600 $\mu \mathrm{M}$ hydrogen peroxide) (Fig. $4 \mathrm{~A}$ ) or kinase inhibition ( $1 \mu \mathrm{M}$ STS) (Fig. $4 \mathrm{~B}$ ). $\mathrm{H}_{2} \mathrm{O}_{2}$-induced cell death was almost completely inhibited in $\mathrm{bim}^{-1-}$ explants. Figure $4 \mathrm{C}$ illustrates in graph format the dramatic protection observed in $-/-$ explants, whereas $+/-$ explants exhibit an intermediate effect in response to both A23187 and $\mathrm{H}_{2} \mathrm{O}_{2}$. Interestingly, there is a statistically significant difference between the number of TUNEL-positive cells in untreated wt explants compared with the number in untreated $-/-$ explants $(p<0.01)$.

STS treatment induced apoptosis in the both the ONL and INL, giving us the opportunity to observe the effect in both layers. We discovered that the absence of Bim affords protection in both layers (Fig. 4B). The GCL is also protected in the STS model, but optic nerve transection also contributes to cell death in this retinal layer. Therefore, the absence of Bim could be affording protection against STS, optic nerve transection, or both. This laboratory previously showed that the adult GCL is protected from axotomy in the absence of Bim (McKernan and Cotter, 2007); therefore, counts of TUNEL-positive cells were compared in untreated wt and $\mathrm{bim}^{-/-} \mathrm{P} 15$ retinal explants. Results suggest that there is $50-60 \%$ protection of the GCL in P15 explants, and thus Bim contributes to death by axotomy (data not shown). 
Reduced Bim expression correlates with a switch to caspase-independent apoptosis in the rd model

Publications from this laboratory and others have shown that cell death in the retinal degeneration ( $\mathrm{rd}$ ) model of retinitis pigmentosa, in which calcium stress is an apical event, does not require caspase activation (Zeiss et al., 2004; Doonan et al., 2005; Paquet-Durand et al., 2006). Figure 5A shows the pattern of cell death at specific time points during postnatal development (P7 and P8) and degeneration (P12 and $\mathrm{P} 14)$ of the rd mouse retina. Caspase- 9 activity was detected by immunohistochemical analysis with an antibody specific to cleaved caspase-9 during development of the rd retina but not during degeneration. These data clearly demonstrate that cells of the retina are capable of using different cell death programs. Protein lysates from rd retinas analyzed for BimEL, demonstrated that expression of this protein decreased markedly during development of the rd retina between $\mathrm{P} 8$ and $\mathrm{P} 9$ and was not reexpressed during degeneration (Fig. 5B). In fact, BimEL was downregulated in the rd retina even earlier than wt, $\mathrm{P} 8-\mathrm{P} 9$ compared with P11-P12. Transcription of the bim gene had also ceased at $\mathrm{P} 8$ and up to P14 had not resumed (Fig. 5C). Therefore, the absence of Bim expression correlates with the absence of cytochrome $c$ release (Doonan et al., 2003) and caspasedependent apoptosis in the rd mouse. To determine whether or not caspase mechanisms remain intact in the rd mouse, we attempted to force Bim expression in rd retinal explants by addition of calcium. Rd retinas were explanted at P11 and either left untreated or treated for $24 \mathrm{~h}$ with $1 \mu \mathrm{M}$ A23187. Cleaved caspase- 9 was detected by immunohistochemistry in A23187-treated rd retinas but not in untreated retinas despite the presence of TUNEL-positive cells (Fig. 5D). We also observed an increase in Bim expression by Western blot, indicating that the presence of Bim correlates with caspase activation (Fig. 5E).

These data combined with the $\mathrm{bim}^{-/-}$studies suggest that Bim plays an important role in caspase-dependent retinal cell death and may thus explain why death in the rd retina does not involve caspase activation. We are certain from our work with cell-free extracts that the mitochondrial pathway can be activated, but is not activated because of a block at the level of cytochrome $c$ release (Doonan et al., 2003). This supports the evidence presented here that the downregulation of Bim and potentially other $\mathrm{BH} 3$-only proteins is an important checkpoint for activation of mitochondrial pathway.

\section{Discussion}

An important role for Bim in many neuronal paradigms and in lymphoid cell death has been described in the literature (Bouillet et al., 1999; Putcha et al., 2001; Linseman et al., 2002; Gilley et al., 2003; Erlacher et al., 2005; Hutcheson et al., 2005). Here, we describe, for the first time, an important role for Bim during

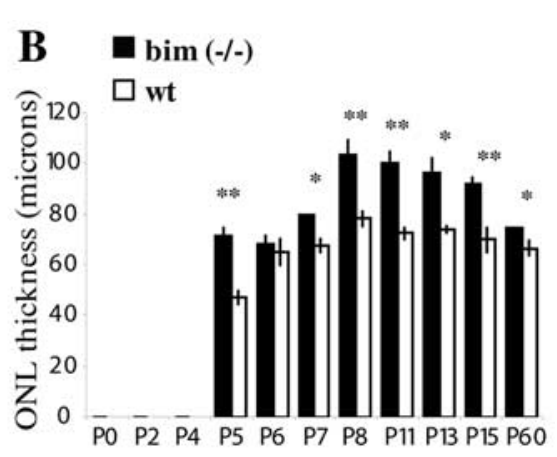

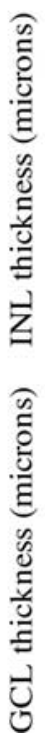



Figure 2. bim $^{-/-}$retinas are thicker than their wt counterparts. $\boldsymbol{A}$, Retinal sections from wt and bim $^{-/-}$mice at P2, P5, P13, and P60 were stained with an antibody reactive to cleaved caspase- 9 . Caspase- 9 processing is detectable in wt and bim ${ }^{-1-}$ retinas, as indicated by the arrows. $\boldsymbol{B}$, Thickness of the $0 \mathrm{NL}$, INL, and $\mathrm{GCL}$ in micrometers measured with a calibrated scale of the objective of the light microscope. NBL, Neuroblastic layer. Comparisons between bim $^{-1-}$ and wt were performed using unpaired, two-tailed $t$ test analysis. Error bars represent $\pm S D\left({ }^{*} p<0.05 ;{ }^{* *} p<0.01 ;{ }^{* * *} p<0.001\right)$.

postnatal development of the mouse retina. From birth, bim $^{-1-}$ retinas mice exhibit a clear increase in thickness, which is still evident in the ONL at later stages of development. We showed that increased thickness of $\mathrm{bim}^{-/-}$retinas is a result of decreased developmental apoptosis at early postnatal ages. This is not unexpected given the potent proapoptotic function of this gene. The first wave of retinal PCD, occurring in the GCL, is delayed by a number of days in $\mathrm{bim}^{-1-}$ retinas as are the subsequent waves of postnatal cell death eliminating cells of the INL and ONL. A transient delay such as this, is consistent with a report describing a temporary delay in developmental apoptosis in dorsal root ganglion cells from bim ${ }^{-1-}$ mice in vivo (Putcha et al., 2001).

Thus, our data indicate a dependence on Bim for the progression of normal retinal development, through the removal of excess cells by apoptosis, in both the embryonic and postnatal phase. We hypothesize that Bim is a critical $\mathrm{BH} 3$-only protein on which developmental death signals converge in retinal neurons, and the absence of this protein significantly delays apoptosis. However, the protection conferred by Bim deficiency is transient, and retinal cells in the $\mathrm{bim}^{-/-}$mouse still die, albeit at a slower rate, via the intrinsic pathway (verified by caspase- 9 cleavage). Therefore, alternate mechanisms seem to exist that allow resumption of normal development, presumably involving recruitment of other BH3-only proteins upstream of the Bax/Bcl-2 checkpoint that are capable of responding to the death stimulus 
$\mathbf{A}$
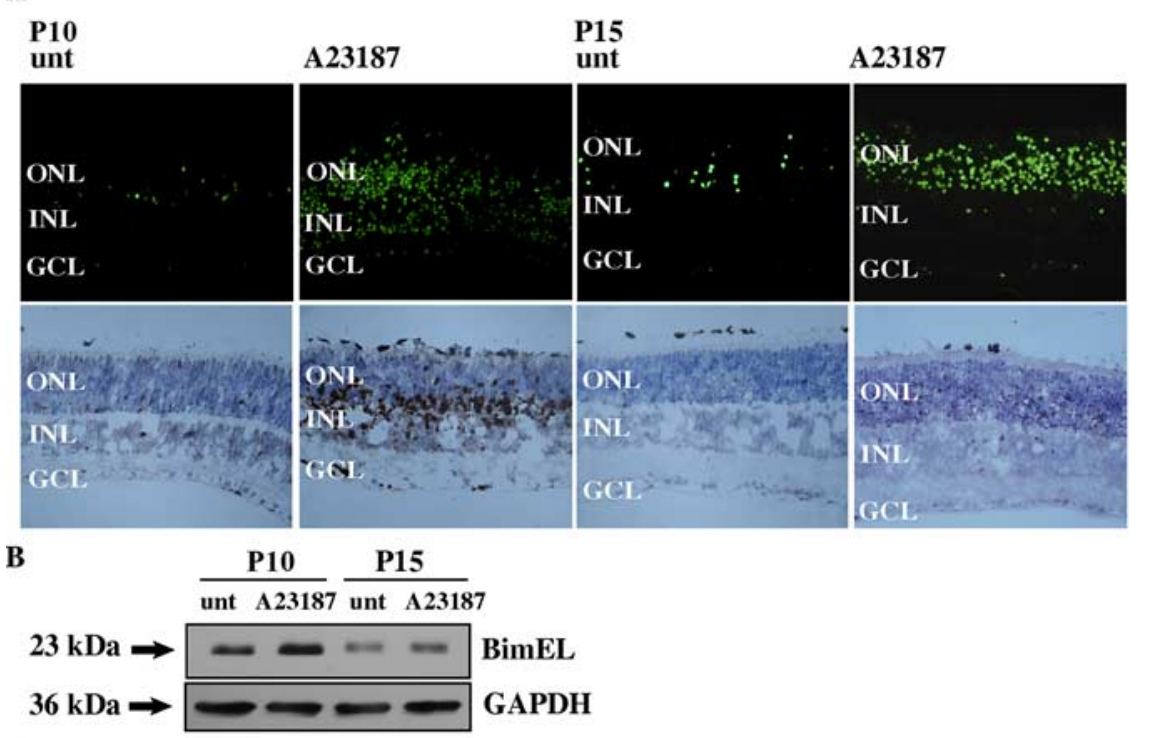

C P15 unt
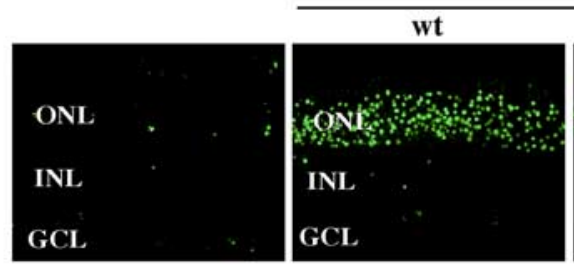

D

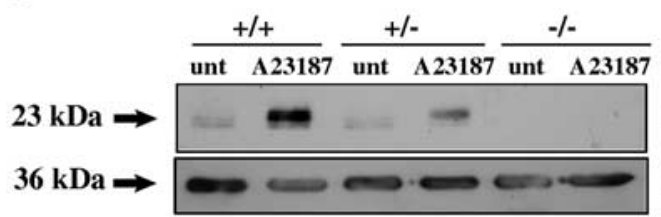

BimEL

GAPDH
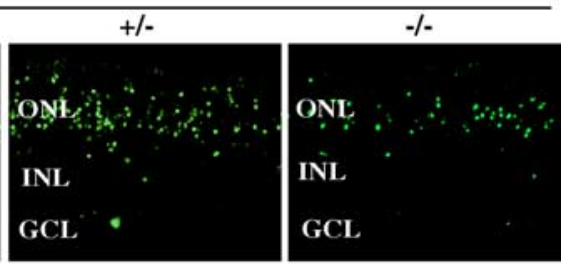

E $\quad \mathbf{A 2 3 1 8 7} \%$

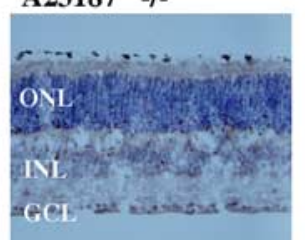

Figure 3. Bim-deficient retinal explants are resistant to calcium overload. $\boldsymbol{A}$, TUNEL staining and immunohistochemistry for cleaved caspase-9 in retinal sections from untreated (unt) and calcium ionophore-treated (A23187; $5 \mu \mathrm{M}$ ) P10 and P15 explants after $24 \mathrm{~h}$. P10 explants are more susceptible to cell death and caspase activation than P15 explants. B, Western blot analysis of Bim expression in untreated and treated $(A 23187 ; 5 \mu \mathrm{M}) \mathrm{P} 10$ and P15 retinal explants after $24 \mathrm{~h}$. Blots were reprobed with GAPDH to demonstrate equal protein loading. C, D, TUNEL staining of retinal sections and Western blot analysis of Bim expression from untreated wt and A23187-treated wt, bim $^{+/-}(+/-)$, and bim $^{-/-}(-/-)$explants after $24 \mathrm{~h}$. E, Immunohistochemistry for cleaved caspase-9 in a retinal section from A23187-treated $\mathrm{bim}^{-/-}(-/-)$explants.

in the absence of Bim. This has been described in DNA-damaged lymphocytes in vivo in which both Puma and Bim contribute significantly to cell death (Erlacher et al., 2005). Similarly, spermatogenesis is arrested in adult mice lacking both Bik and Bim, whereas mice lacking only one gene exhibit no adverse effects (Coultas et al., 2005; Erlacher et al., 2005). Interestingly, retinas from Bax/Bak double knock-outs remain markedly thicker at 2 months (and 8 months) of age, whereas there is very little discernable difference in bim $^{-1-}$ retinas. This indicates an absolute dependence on the mitochondrial pathway for normal retinal development and certainly supports the theory that BH3-only proteins other than Bim may be involved (Hahn et al., 2003; Pequignot et al., 2003).

Despite the apparent redundancy in $\mathrm{BH} 3$-only proteins during retinal development, retinas of Bim knock-out mice are protected against $80-90 \%$ of cell death in response to diverse stimuli. There have been many reports in the literature suggesting that the involvement of individual $\mathrm{BH} 3$-only proteins in the initiation of apoptosis is stimulus-specific. For example, Bim is activated in response to cytokine withdrawal and calcium flux (Bouillet et al., 1999; Puthalakath et al., 1999), Bmf is activated by loss of cellular attachment (anoikis) (Puthalakath et al., 2001), and both Puma and Noxa are activated in response to DNA damage (Erster et al., 2004; Wyttenbach and Tolkovsky, 2006). This laboratory has previously demonstrated that Bim expression is rapidly induced in a photoreceptor cell line in response to serum starvation and UV light resulting in caspasedependent cell death (Gomez-Vicente et al., 2006). However, this study is the first to show that retinal explants from $\mathrm{bim}^{-/-}$ mice are resistant to caspase-dependent apoptosis in response to a variety of death stimuli, including calcium overload, protein kinase inhibition, and oxidative stress. Bim certainly does appear to be the limiting factor for activation of cell death in retinal explants because a gene dosage effect was consistently observed in heterozygotes, which died at an intermediate rate between that of wt and $\mathrm{bim}^{-1-}$ (Fig. 3C). However, for each set of data with the exception of STS-treated ONL, the level of cell death in treated bim $^{-/-}$explants remains slightly higher than in untreated explants and those cells that are dying stain positive for caspases (Fig. 3E) (data not shown for hydrogen peroxide and STS). Whether or not caspase activation in the remaining TUNEL-positive cells is attributable to other $\mathrm{BH} 3$-only proteins remains unclear.

Thus, Bim appears to play a dominant role in stimulus-induced death in retinal explants, despite the fact that numerous $\mathrm{BH} 3$-only proteins have been described. The particular potency of Bim as a death inducer can probably be attributed to its ability to strongly bind and neutralize all prosurvival $\mathrm{Bcl}-2$ proteins $\left(\mathrm{Bcl}-2, \mathrm{Bcl}-\mathrm{x}_{\mathrm{L}}\right.$, Bcl-w, Mcl-1, and A1). The same is true for Puma and tBid, whereas other $\mathrm{BH} 3$-only proteins exhibit clear selectivity (Chen et al., 2005). For example, the complementary binding profiles of $\mathrm{Bad}\left(\mathrm{Bcl}-2, \mathrm{Bcl}-\mathrm{x}_{\mathrm{L}}\right.$, and $\left.\mathrm{Bcl}-\mathrm{w}\right)$ and Noxa ( $\mathrm{Mcl}-1$ and $\mathrm{A} 1$ ) suggest that alone they are inefficient killers but in combination work very effectively to induce apoptosis (Willis et al., 2005). In this model, BH3-only proteins activate Bak (and possibly Bax in the same manner) simply by sequestering the prosurvival Bcl-2 family proteins to which Bak is bound. An alternative model suggests that $\mathrm{BH} 3$-only proteins can be divided into two subclasses; "sensitizers" (e.g., Bik), which inactivate the prosurvival proteins, and "activators" (Bim and tBid), which directly bind and activate Bax and Bak (Letai et al., 2002). However, the observations leading to the conception of this model could equally be explained by the superior ability of Bim and tBid to inactivate prosurvival proteins present at the mitochondria.

Despite the evidence that Bim and the mitochondrial pathway play an essential role in both development and stimulusinduced cell death in explants, degenerating photoreceptors in 
the rd model execute caspaseindependent death. We showed previously that caspase- 9 and -3 are not activated during degeneration in the $\mathrm{rd}$ mouse possibly because of a block at the level of cytochrome $c$ release (Doonan et al., 2003; Donovan et al., 2006). In this study, our results demonstrate that the expression of Bim decreases rapidly in the developing rd mouse retina and is not reexpressed during degeneration. Forced reexpression of Bim ex vivo converts the pathway to one in which caspases are active (Fig. $5 D, E$ ), indicating that caspase-dependent mechanisms are intact in the rd mouse in vivo but perhaps cannot respond to an initiation signal at the level of the mitochondria. This could be attributable to absence of $\mathrm{Bim}$, and other $\mathrm{BH} 3$-only proteins preventing mitochondrial pore formation, and release of proapoptotic factors. Interestingly, differentiated cardiomyocytes demonstrate resistance to caspasedependent cell death because elements of the caspase-dependent pathway are silenced during heart development. Using ischemia as a trigger, caspase activation was shown in embryonic cardiomyocytes and proliferating fibroblasts but not in neonatal and adult cardiomyocytes (Bahi et al., 2006). Similar findings have been reported in Drosophila carry-

ing a mutation in the norpA gene, causing retinal degeneration (Hsu et al., 2004). IAP (inhibitor of apoptosis) antagonists grim, rpr, and hid, which are common inducers of developmental PCD, are not necessary for adult retinal degeneration. In addition, expression of the caspase inhibitor p35 does not alter the progression of apoptosis, indicating that the pathways typically responsible for developmental PCD do not play an essential role in norpA-induced degeneration. Thus, the same neuronal population can use different developmental and pathologic cell death pathways. Therefore, we propose that proteins such as Bim, abundantly expressed for the purpose of developmental apoptosis, are downregulated to avoid rapid caspase activation and cell death, which could have serious implications for the maturing retina. Hence, two options are available to photoreceptors in response to apoptotic stimuli. First, components required for caspase-dependent apoptosis may be reexpressed; for instance, Bim and Hrk are upregulated in axotomized retinal ganglion cells before apoptosis (Wakabayashi et al., 2002; Napankangas et al., 2003). Alternatively, a caspase-independent death pathway, which we observed in a number of models of retinal degeneration, may be activated.

In conclusion, the present findings indicate that caspases are the primary executioners of developmental retinal cell death and indeed most of the stimulus-induced apoptosis in early postnatal retinas in vitro. However, termination of developmental apoptosis in the retina appears to initiate downregulation of the Bcl-2 family member Bim, a key intermediary in caspase-dependent death. Reexpression of Bim in retinal explants appears to reactivate developmental cell death pathways. However, in certain in vivo models, such as the rd model in which this does not occur, photoreceptor cells are capable of dying independently of caspases.

\section{References}

Bahi N, Zhang J, Llovera M, Ballester M, Comella JX, Sanchis D (2006) Switch from caspase-dependent to -independent death during heart development: essential role of EndoG in ischemia-induced DNA processing of differentiated cardiomyocytes. J Biol Chem 281:22943-22952.

Biswas SC, Greene LA (2002) Nerve growth factor (NGF) down-regulates the $\mathrm{Bcl}-2$ homology 3 (BH3) domain-only protein Bim and suppresses its proapoptotic activity by phosphorylation. J Biol Chem 277:49511-49516.

Bouillet P, Metcalf D, Huang DC, Tarlinton DM, Kay TW, Kontgen F, Adams JM, Strasser A (1999) Proapoptotic Bcl-2 relative Bim required for certain apoptotic responses, leukocyte homeostasis, and to preclude autoimmunity. Science 286:1735-1738.

Chahory S, Padron L, Courtois Y, Torriglia A (2004) The LEI/L-DNase II pathway is activated in light-induced retinal degeneration in rats. Neurosci Lett 367:205-209.

Chen L, Willis SN, Wei A, Smith BJ, Fletcher JI, Hinds MG, Colman PM, Day CL, Adams JM, Huang DC (2005) Differential targeting of prosurvival $\mathrm{Bcl}-2$ proteins by their $\mathrm{BH} 3$-only ligands allows complementary apoptotic function. Mol Cell 17:393-403.

Cheng EH, Wei MC, Weiler S, Flavell RA, Mak TW, Lindsten T, Korsmeyer SJ (2001) BCL-2, BCL-X(L) sequester BH3 domain-only molecules preventing BAX- and BAK-mediated mitochondrial apoptosis. Mol Cell 8:705-711.

Coultas L, Bouillet P, Loveland KL, Meachem S, Perlman H, Adams JM, Strasser A (2005) Concomitant loss of proapoptotic BH3-only Bcl-2 antagonists Bik and Bim arrests spermatogenesis. EMBO J 24:3963-3973.

Danial NN, Korsmeyer SJ (2004) Cell death: critical control points. Cell 116:205-219.

Dijkers PF, Birkenkamp KU, Lam EW, Thomas NS, Lammers JW, Koenderman L, Coffer PJ (2002) FKHR-L1 can act as a critical effector of cell death induced by cytokine withdrawal: protein kinase B-enhanced cell 
$\mathbf{A}$
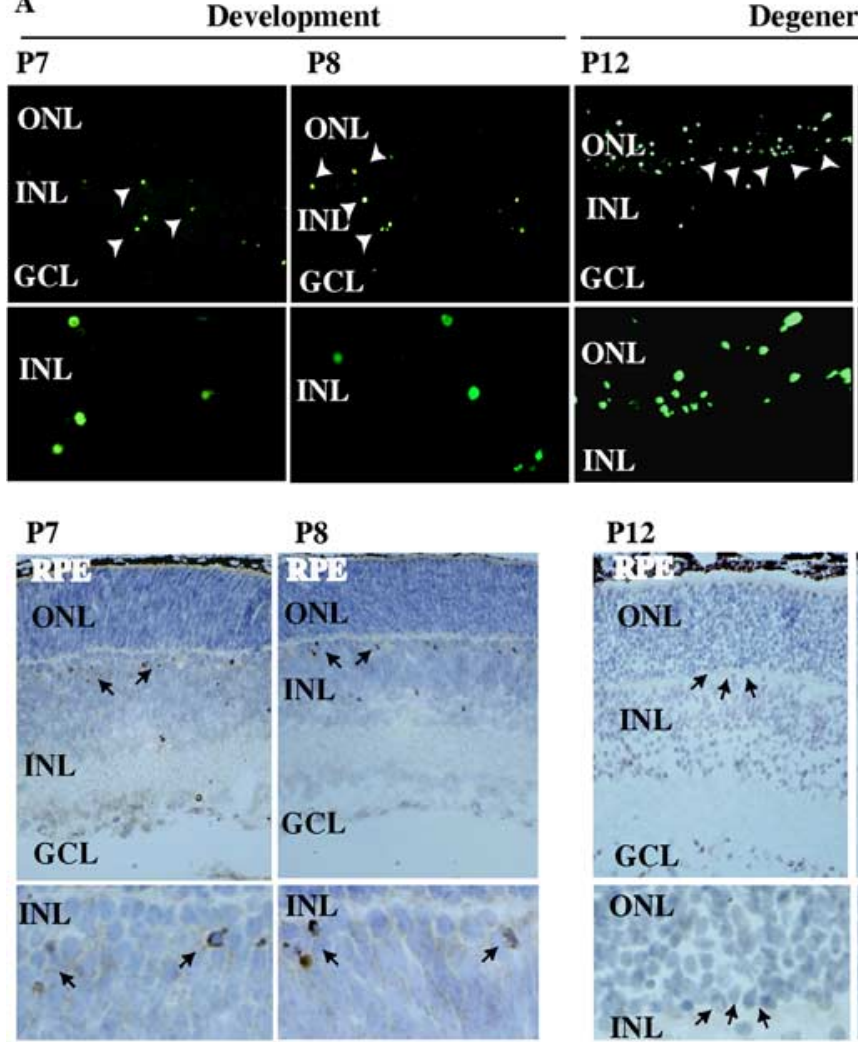



B

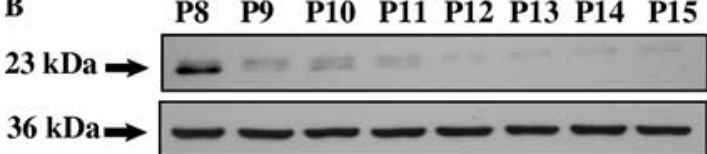

D


rd P12

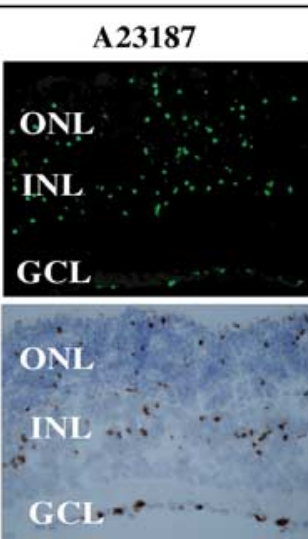

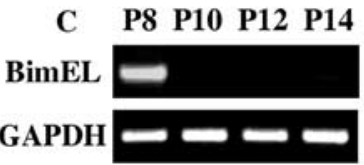

$\mathbf{E}$ unt $\mathbf{A 2 3 1 8 7}$



BimEL

GAPDH

Figure 5. Caspase-independent cell death in the rd mouse correlates with Bim downregulation. $\boldsymbol{A}$, TUNEL staining (arrowheads) and immunohistochemistry for cleaved caspase-9 (arrows) in the rd mouse retina during development (P7 and P8) and degeneration (P12 and P14). B, Western blot analysis of Bim expression in the rd retina from P8 to P15. Blots were reprobed with GAPDH to demonstrate equal protein loading. C, Semiquantitative RT-PCR of bimEL in the rd retina with gapdh as a loading control. D, TUNEL staining and immunohistochemistry for cleaved caspase-9 in retinal sections from untreated ( $24 \mathrm{~h}$ ) and A23187-treated (1 $\mu \mathrm{M}$ for $24 \mathrm{~h}$ ) rd P12 explants. E, Western blot analysis of Bim expression in untreated and A23187-treated (1 $\mu \mathrm{m}$ for $24 \mathrm{~h}$ ) rd retinas at $\mathrm{P} 12$.

Donovan M, Doonan F, Cotter TG (2006) Decreased expression of pro-apoptotic Bcl-2 family members during retinal development and differential sensitivity to cell death. Dev Biol 291:154-169.

Doonan F, Donovan M, Cotter TG (2003) Caspase-independent photoreceptor apoptosis in mouse models of retinal degeneration. J Neurosci 23:5723-5731.

Doonan F, Donovan M, Cotter TG (2005) Activation of multiple pathways during photoreceptor apoptosis in the rd mouse. Invest Ophthalmol Vis Sci 46:3530-3538.

Dunaief JL, Dentchev T, Ying GS, Milam AH (2002) The role of apoptosis in age-related macular degeneration. Arch Ophthalmol 120:1435-1442.

Erlacher M, Michalak EM, Kelly PN, Labi V, Niederegger H, Coultas L, Adams JM, Strasser A, Villunger A (2005) BH3-only proteins Puma and Bim are rate-limiting for gammaradiation- and glucocorticoid-induced apoptosis of lymphoid cells in vivo. Blood 106:4131-4138.

Erster S, Mihara M, Kim RH, Petrenko O, Moll UM (2004) In vivo mitochondrial p53 translocation triggers a rapid first wave of cell death in response to DNA damage that can precede p53 target gene activation. Mol Cell Biol 24:6728-6741.

Fox DA, Poblenz AT, He L, Harris JB, Medrano CJ (2003) Pharmacological strategies to block rod photoreceptor apoptosis caused by calcium overload: a mechanistic target-site approach to neuroprotection. Eur J Ophthalmol 13 [Suppl 3]:S44-S56.

Gilley J, Coffer PJ, Ham J (2003) FOXO transcription factors directly activate bim gene expression and promote apoptosis in sympathetic neurons. J Cell Biol 162:613-622.

Gomez-Vicente V, Doonan F, Donovan M, Cotter TG (2006) Induction of BIM(EL) following growth factor withdrawal is a key event in caspase-dependent apoptosis of $661 \mathrm{~W}$ photoreceptor cells. Eur J Neurosci 24:981-990.

Hahn P, Lindsten T, Ying GS, Bennett J, Milam AH, Thompson CB, Dunaief JL (2003) Proapoptotic bcl-2 family members, Bax and Bak, are essential for developmental photoreceptor apoptosis. Invest Ophthalmol Vis Sci 44:3598-3605.

Harris CA, Johnson Jr EM (2001) BH3-only $\mathrm{Bcl}-2$ family members are coordinately regulated by the JNK pathway and require Bax to induce apoptosis in neurons. J Biol Chem 276:37754-37760.

Hsu CD, Whaley MA, Frazer K, Miller DA, Mitchell KA, Adams SM, O’Tousa JE (2004) Limited role of developmental programmed cell death pathways in Drosophila norpA retinal degeneration. J Neurosci 24:500-507.

Hutcheson J, Scatizzi JC, Bickel E, Brown NJ, Bouillet P, Strasser A, Perlman H (2005) Combined loss of proapoptotic genes Bak or Bax with Bim synergizes to cause defects in hematopoiesis and in thymocyte apoptosis. J Exp Med 201:1949-1960.

survival through maintenance of mitochondrial integrity. J Cell Biol 156:531-542.

Donovan M, Carmody RJ, Cotter TG (2001) Light-induced photoreceptor apoptosis in vivo is caspase independent and mediated by nitric oxide. ScientificWorldJournal 1:52.
Letai A, Bassik MC, Walensky LD, Sorcinelli MD, Weiler S, Korsmeyer SJ (2002) Distinct BH3 domains either sensitize or activate mitochondrial apoptosis, serving as prototype cancer therapeutics. Cancer Cell 2:183-192. 
Ley R, Balmanno K, Hadfield K, Weston C, Cook SJ (2003) Activation of the ERK1/2 signaling pathway promotes phosphorylation and proteasomedependent degradation of the BH3-only protein, Bim. J Biol Chem 278:18811-18816.

Li Z, Milam A (1995) Degenerative diseases of the retina. New York: Plenum.

Linseman DA, Phelps RA, Bouchard RJ, Le SS, Laessig TA, McClure ML, Heidenreich KA (2002) Insulin-like growth factor-I blocks Bcl-2 interacting mediator of cell death (Bim) induction and intrinsic death signaling in cerebellar granule neurons. J Neurosci 22:9287-9297.

Lohr HR, Kuntchithapautham K, Sharma AK, Rohrer B (2006) Multiple, parallel cellular suicide mechanisms participate in photoreceptor cell death. Exp Eye Res 83:380-389.

Luciano F, Jacquel A, Colosetti P, Herrant M, Cagnol S, Pages G, Auberger P (2003) Phosphorylation of Bim-EL by Erk1/2 on serine 69 promotes its degradation via the proteasome pathway and regulates its proapoptotic function. Oncogene 22:6785-6793.

McKernan DP, Cotter TG (2007) A critical role for Bim in retinal ganglion cell death. J Neurochem 102:922-930.

Napankangas U, Lindqvist N, Lindholm D, Hallbook F (2003) Rat retinal ganglion cells upregulate the pro-apoptotic BH3-only protein Bim after optic nerve transection. Brain Res Mol Brain Res 120:30-37.

Obexer P, Geiger K, Ambros PF, Meister B, Ausserlechner MJ (2007) FKHRL1-mediated expression of Noxa and Bim induces apoptosis via the mitochondria in neuroblastoma cells. Cell Death Differ 14:534-547.

O’Connor L, Strasser A, O’Reilly LA, Hausmann G, Adams JM, Cory S, Huang DC (1998) Bim: a novel member of the Bcl-2 family that promotes apoptosis. EMBO J 17:384-395.

Paquet-Durand F, Azadi S, Hauck SM, Ueffing M, van Veen T, Ekstrom P (2006) Calpain is activated in degenerating photoreceptors in the $\mathrm{rd} 1$ mouse. J Neurochem 96:802-814.

Pequignot MO, Provost AC, Salle S, Taupin P, Sainton KM, Marchant D, Martinou JC, Ameisen JC, Jais JP, Abitbol M (2003) Major role of BAX in apoptosis during retinal development and in establishment of a functional postnatal retina. Dev Dyn 228:231-238.

Putcha GV, Moulder KL, Golden JP, Bouillet P, Adams JA, Strasser A, Johnson EM (2001) Induction of BIM, a proapoptotic BH3-only BCL-2 family member, is critical for neuronal apoptosis. Neuron 29:615-628.

Puthalakath H, Huang DC, O'Reilly LA, King SM, Strasser A (1999) The proapoptotic activity of the Bcl-2 family member Bim is regulated by interaction with the dynein motor complex. Mol Cell 3:287-296.

Puthalakath H, Villunger A, O'Reilly LA, Beaumont JG, Coultas L, Cheney
RE, Huang DC, Strasser A (2001) Bmf: a proapoptotic BH3-only protein regulated by interaction with the myosin $\mathrm{V}$ actin motor complex, activated by anoikis. Science 293:1829-1832.

Quigley HA, Nickells RW, Kerrigan LA, Pease ME, Thibault DJ, Zack DJ (1995) Retinal ganglion cell death in experimental glaucoma and after axotomy occurs by apoptosis. Invest Ophthalmol Vis Sci 36:774-786.

Read DS, McCall MA, Gregg RG (2002) Absence of voltage-dependent calcium channels delays photoreceptor degeneration in rd mice. Exp Eye Res 75:415-420.

Takano Y, Ohguro H, Dezawa M, Ishikawa H, Yamazaki H, Ohguro I, Mamiya K, Metoki T, Ishikawa F, Nakazawa M (2004) Study of drug effects of calcium channel blockers on retinal degeneration of rd mouse. Biochem Biophys Res Commun 313:1015-1022.

Wakabayashi T, Kosaka J, Hommura S (2002) Up-regulation of Hrk, a regulator of cell death, in retinal ganglion cells of axotomized rat retina. Neurosci Lett 318:77-80.

Wang K, Yin XM, Chao DT, Milliman CL, Korsmeyer SJ (1996) BID: a novel BH3 domain-only death agonist. Genes Dev 10:2859-2869.

Wei MC, Zong WX, Cheng EH, Lindsten T, Panoutsakopoulou V, Ross AJ, Roth KA, MacGregor GR, Thompson CB, Korsmeyer SJ (2001) Proapoptotic BAX and BAK: a requisite gateway to mitochondrial dysfunction and death. Science 292:727-730.

Whitfield J, Neame SJ, Paquet L, Bernard O, Ham J (2001) Dominantnegative c-Jun promotes neuronal survival by reducing BIM expression and inhibiting mitochondrial cytochrome c release. Neuron 29:629-643.

Willis SN, Chen L, Dewson G, Wei A, Naik E, Fletcher JI, Adams JM, Huang DC (2005) Proapoptotic Bak is sequestered by Mcl-1 and Bcl-xL, but not Bcl-2, until displaced by BH3-only proteins. Genes Dev 19:1294-1305.

Wyttenbach A, Tolkovsky AM (2006) The BH3-only protein Puma is both necessary and sufficient for neuronal apoptosis induced by DNA damage in sympathetic neurons. J Neurochem 96:1213-1226.

Young RW (1984) Cell death during differentiation of the retina in the mouse. J Comp Neurol 229:362-373.

Zeiss CJ, Neal J, Johnson EA (2004) Caspase-3 in postnatal retinal development and degeneration. Invest Ophthalmol Vis Sci 45:964-970.

Zha J, Harada H, Osipov K, Jockel J, Waksman G, Korsmeyer SJ (1997) BH3 domain of $\mathrm{BAD}$ is required for heterodimerization with BCL-XL and pro-apoptotic activity. J Biol Chem 272:24101-24104.

Zong WX, Lindsten T, Ross AJ, MacGregor GR, Thompson CB (2001) $\mathrm{BH} 3$-only proteins that bind pro-survival $\mathrm{Bcl}-2$ family members fail to induce apoptosis in the absence of Bax and Bak. Genes Dev 15:1481-1486. 